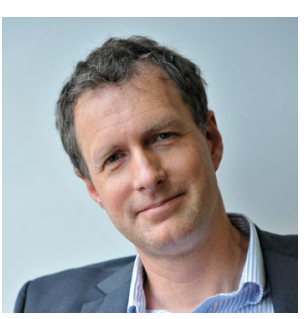

Credit: University of Warwick

\title{
Facing up to the uncertainties of COVID-19
}

\author{
The human tendency to impose a single interpretation in ambiguous situations carries huge \\ dangers in addressing COVID-19. We need to search actively for multiple interpretations, and \\ governments need to choose policies that are robust if their preferred theory turns out to be \\ wrong, argues Nick Chater.
}

$\mathrm{H}$ ow are governments, and individuals, supposed to react to an unprecedent crisis? The impact of COVID-19 is resonating across the world, and yet we know so little about the virus and how people across different parts of the world are modifying their behaviour in response to the threat. Lock-downs in China and South Korea have been remarkably effective, in the short term at least; would the same approach work in, say, Europe, Africa or the US? We don't know, either, whether the virus will flare up as restrictions are released or whether maintaining enhanced hygiene and social distancing, and/or rigorous programs of mass-testing and contact-tracing, might be able to stamp it out.

In situations of extreme uncertainty, our brains struggle to organize this confusing mass of partial and jumbled information into a coherent interpretation. And we make decisions as if that interpretation is true, without entertaining alternatives. This strategy can often serve us pretty well, but sometimes it leads to bad, and even disastrous, decision-making. The misinterpretation of the COVID-19 outbreak has the potential to have devastating consequences.

At its most fundamental level, there are three interpretations of the challenge that face the governments of the world, which we might term 'storm in a tea-cup', 'house on fire' and 'holding back the tide.'

The first interpretation is the mind's natural default: most alarms are false alarms; most panics are overblown-so probably this one is too. China's nownotorious early attempts to suppress news of the outbreak makes sense only in the 'teacup' interpretation; so too does the US's initial downplaying of the crisis with the US President's comment on 24 February that the virus is "very much under control in the USA" (https://twitter.com/realDonaldTrump/ status/1232058127740174339). According to this interpretation of the situation, the main aim is that people do not panic unnecessarily; the problem will resolve itself on its own (for example, with the arrival of warmer weather).

The 'house on fire' interpretation has driven unprecedented lock-downs first in China, South Korea and Japan, followed by Europe and the US. According to this viewpoint, tackling the virus is an overwhelming priority. The economic and social impacts of shutting down or drastically reducing sports, restaurants, pubs, flights and much more will be vast but have to be endured, rather like collateral water damage, however severe, caused by the firefighter's hose. This interpretation of the situation also implies taking the strongest action as early as possible. The right time to start fighting a fire is: immediately!

The UK government, until the Prime Minister's press conference on Monday 16 March, appeared to be working with the third narrative. The 'holding back the tide' viewpoint sees beating down the virus as workable only as a temporary stop-gap: we can build temporary defences against a rising tide, but inundation is unavoidable. If this is right, containment of the virus is not ultimately possible. So our aims should be to minimize the impact of its spread, by, for example, actively 'flattening the peak' to manage the burden on health-services, and to reduce the possibility of flare-up during winter, when those services are under most strain. The end-game would be herd immunity, which would be hoped to set in when perhaps $60-80 \%$ of the population had been infected by, and recovered from, the virus. From this point of view, immediate aggressive countermeasures may not be appropriate-what is required is a staged approach, to manage the smoothest possible progress of the virus through the population.

The tendency to lock on to a single narrative and make decisions on that basis is, on reflection, an elementary blunder. Indeed, the psychologist Philip JohnsonLaird has described this tendencyconsidering only one model of the world and failing to search for, or even consider, the existence of any others-as perhaps the most fundamental error in human reasoning. What we should do instead, of course, is recognize when we don't know which interpretation is right and make decisions that are as robust as possible, whichever interpretation turns out to be correct.

In the early days and weeks of COVID-19, the 'tea-cup' interpretation may have seemed credible-even perhaps the most credible-to many. But given the serious possibility that the other, much more alarming, interpretation might be correct, immediately engaging in extensive precautionary measures would seem essential (at a minimum, ramping up production of ventilators, extracorporeal membrane oxygenation (ECMO) machines and personal protective equipment, but also engaging in rapid travel restrictions, as brought in early by the US).

The evidence is now clear: the 'tea-cup' interpretation is decisively falsified. But can we beat the virus back? Is this a containable fire or an inevitable rising tide? The truth is that governments and scientists can't yet be sure. But by not making the most strenuous efforts to put out the fire immediately, we will certainly fail, with the unnecessary loss of hundreds of thousands of lives. The science will become clearer, countermeasures will be further developed and health systems better prepared over the coming months. Whether we can ultimately succeed in eliminating or neutralizing COVID-19 for good, the rational policy response is to fight it now, with everything we have.

\section{Nick Chater}

Professor of Behavioural Science, Warwick Business

School, University of Warwick, Coventry, UK.

e-mail: Nick.Chater@wbs.ac.uk

Published online: 27 March 2020

https://doi.org/10.1038/s41562-020-0865-2

Competing interests

Nick Chater is a paid member of the UK Committee on Climate Change and is co-founder and director of the research consultancy Decision Technology Ltd. 